\title{
Robot technology identifies a Parkinsonian therapeutics repurpose to target stem cells of glioblastoma
}

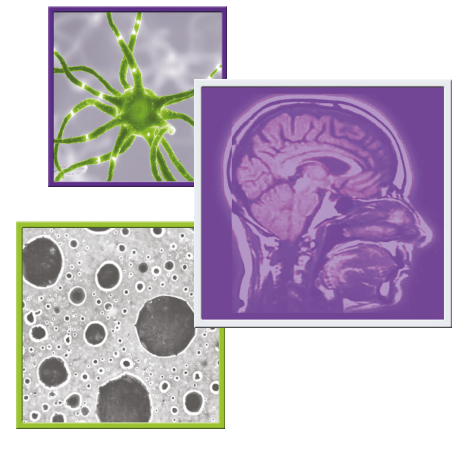

\author{
Andres Vargas-Toscano' ${ }^{10}$, Dilaware Khan ${ }^{1}$, Ann-Christin Nickel', Michael Hewera' ${ }^{1}$ \\ Marcel Alexander Kamp ${ }^{1}$, Igor Fischer ${ }^{1}$, Hans-Jakob Steiger ${ }^{1}$, Wei Zhang ${ }^{3}$, Sajjad \\ Muhammad $^{1}$, Daniel Hänggi ${ }^{1}$ \& Ulf Dietrich Kahlert*,1,2,3 (iD \\ ${ }^{1}$ Clinic for Neurosurgery, Medical Faculty, Heinrich-Heine University Düsseldorf, 40225, Germany \\ ${ }^{2}$ German Consortium for Translational Cancer Research (DKTK), Essen/Düsseldorf, 45147, Germany \\ ${ }^{3}$ Beijing Neurosurgical Institute, Capital Medical University, Beijing, 100050, PR China \\ *Authors for correspondence: Tel.: +49 21181080 13; Ulf.Kahlert@med.uni-duesseldorf.de; mail@ulf-kahlert.com
}

\begin{abstract}
Aim: Glioblastoma is a heterogeneous lethal disease, regulated by a stem-cell hierarchy and the neurotransmitter microenvironment. The identification of chemotherapies targeting individual cancer stem cells is a clinical need. Methodology: A robotic workstation was programmed to perform a drug concentration to cell-growth analysis on an in vitro model of glioblastoma stem cells (GSCs). Mode-of-action analysis of the selected top substance was performed with manual repetition assays and acquisition of further parameters. Results: We identified 22 therapeutic potential substances. Three suggested a repurpose potential of neurotransmitter signal-modulating agents to target GSCs, out of which the Parkinson's therapeutic trihexyphenidyl was most effective. Manual repetition assays and initial mode of action characterization revealed suppression of cell proliferation, cell cycle and survival. Conclusion: Anti-neurotransmitter signaling directed therapy has potential to target GSCs. We established a drug testing facility that is able to define a mid-scale chemo responsome of in vitro cancer models, possibly also suitable for other cell systems.
\end{abstract}

First draft submitted: 11 March 2020; Accepted for publication: 6 May 2020; Published online:

28 May 2020

Keywords: cancer stem-like cells $\bullet$ drug repurposing $\bullet$ glioblastoma $\bullet$ in vitro pharmacogenomics $\bullet$ neurotransmitters $\bullet$ personalized medicine $\bullet$ robot $\bullet$ translational research

Cancer is a global health problem for which the most frequently used treatment is chemotherapy. Given the molecular and cellular heterogeneity of cancer as an entity, the identification of tailored chemotherapies for each individual tumor is considered to improve the response to treatment $[1,2]$. In this study, we focus on glioblastoma, the most frequent malignant primary brain tumor and one of the most lethal cancers [3]. Tumors, including glioblastoma, are thought be organized in a hierarchical manner with cells possessing stem cell properties which are the main determinants of disease malignancy and progression. Moreover, the interaction of tumor cells with the microenvironment is believed to determine tumor therapy resistance $[4,5]$. Consequently, there is growing evidence suggesting a strong relationship between brain cancer and the neurotransmitter microenvironment and intervening in these signals was recently suggested as a promising strategy to fight the disease $[4,6]$.

In vitro pharmacologic testing is an early stage of drug development and is the fundament of various in vitrodiagnostic technologies. Liquid handling systems allow large-scale, reproducible and accurate allocation of solved components and represent a standard tool in both industry laboratories and routine diagnostics [7]. By using an embedded robotic automation equipment, we applied an industry-standard technology into an academic preclinical research laboratory and performed a medium-size screening analysis by correlating drug-concentration with cellgrowth. We established a screening library composed of market-approved substances with reported blood-brain barrier permeability to potentiate a rapid clinical translation of the results. Using this robotic-based strategy, we 
identified 22 anti-cell-growth compounds, out of which three were neurotransmitter signal-modifying substances, with previously unreported therapeutic relevance in the context of glioblastoma.

\section{Methods}

A custom-made $10 \mathrm{mM}$ drug library (dissolved in dimethyl sulfoxide; DMSO) consisting of 167 US FDA approved, molecularly diverse compounds with reported brain tissue penetration was assembled and purchased (TargetMol, MA, USA; Supplementary Tables $1 \& 2$ ). We programmed the robot to deliver drugs into 384-well plates using duplicate wells for each drug (V-bottom 384-well plates, Axygen, Corning Inc., NY, USA). The prepared plates were sealed and stored at $-80^{\circ} \mathrm{C}$. The following drug concentrations: 100,000, 10,000, 1000, 100 and $10 \mathrm{nM}$ per well, previously diluted in Dulbecco's Modified Eagle's Medium to reduce DMSO content (in concordance with the manufacturer of the compound library) were generated by using a robot-mediated dilution assay. For each dilution, a separate 384-plate was used, and the final dispensed volume was $10 \mu \mathrm{l}$.

For manually executed validation assays, DL-trihexyphenidyl hydrochloride (THP; Sigma Aldrich, MO, USA) was resuspended to a final concentration of $50 \mathrm{mM}$ in methanol, $\mathrm{MeOH}$, (in concordance with the manufacturer instructions), after which serial dilutions for the above mentioned working concentrations were prepared; then it was stored at $+4^{\circ} \mathrm{C}$.

The glioblastoma neurosphere model GBM1 [8,9] was cultured as previously described [10]. Cells were passaged every other day.

The Beckman Coulter Biomek ${ }^{\circledR}$ FxP robotic workstation with attached micro-plate reader (Paradigm, now Molecular Devices, CA, USA) was programmed according to software instructions provided by the manufacturer to perform a high-resolution ( 5 different molar concentrations per substance plus vehicle control) drug response testing through determination of response on cellular growth. We exclusively used the multichannel arm for pipetting.

To determine the compatibility of the cell-growth readout assay and the plastic labware selection with the robotic workstation experiments, we performed manual assays comparing the readout robustness and sensitivity of MTT assay (3-(4,5-dimethylthiazol-2-yl)-2,5-diphenyl tetrazolium bromide; Sigma Aldrich), XTT assay (sodium 3' -[1-(phenylaminocarbonyl)-3,4-tetrazolium]-bis (4-methoxy6-nitro) benzene sulfonic acid hydrate; Abcam, Cambridge, UK) and CellTiter-Glo ${ }^{\circledR}$ (CTG) assay (Promega, Walldorf, Germany) in our robot setup (data not shown). Given the result that the most reliable readouts were of modified CTG (1:1, v:v dilution of CTG solution with PBS [phosphate-buffered saline]) luminescence over XTT and MTT absorbance in this specific set-up (Supplementary Figure 1B \& C), we decided to use CTG as our reporter assay.

First, we determined the optimal cell number to be plated in our setting, ensuring exponential growth rate and maximum signal-to-noise intensity. Therefore, we tested the CTG reporter with 500, 1000, 2000, 3000, 6000, 8000, 10,000 and 15,000 GBM1 cells per well in white 384-well plates (Corning Inc.). On each plate; we included a respective blank control (media, no cells) to normalize the background reading. Single-cell dissociation of the spheres was performed using TrypLE (Thermo Fisher Scientific, MA, USA) and cell counting was performed using Muse $^{\top M}$ Count $\&$ Viability Kit (Luminex, TX, USA). Robotic cell plating was assisted using 96-deep-well plates (Eppendorf, Hamburg, Germany) as reservoirs for cell suspension. The luminescence reagent (CTG) was pipetted immediately afterward and readout was performed after $2 \mathrm{~min}$ of shaking followed by $10 \mathrm{~min}$ of incubation at room temperature. We decided to use 10,000 cells in $40 \mu \mathrm{lmedia} /$ well as our cell plating setup for subsequent robotic in vitro drug screening.

Second, we thawed the pre-assembled drug plates, carefully took off the seals and combined the dispensed drug solution with the cells (for a total volume of $50 \mu \mathrm{l}$; resulting in working drug concentrations of 20,000, 2000, 200, 20 and $2 \mathrm{nM}$ and vehicle control). Cells were then incubated with the drugs for $72 \mathrm{~h}$ in standard culture conditions (humidified $37^{\circ} \mathrm{C}, 5 \% \mathrm{CO}_{2}$ ). Afterward, the plates were placed in the robot deck where $40 \mu \mathrm{l}$ of incubated cells were transferred to our white 384-well readout plates and CTG assay was performed as described. The transfer to white plates maximizes light output signal in the reaction wells and decreases noise signals compared with clear plates (data not shown). Given the fully automated nature of this transfer step, we hypothesize that it would not have introduced additional error or risk of error. All assays were performed in biological quadruplicates.

Third, the raw-values were arranged in a logarithmic dose-response curve with which $\mathrm{IC}_{50}$ concentrations were calculated. Statistically significant responses result in ranking the tested substances according to their therapeutic potential using curve analysis and $\mathrm{IC}_{50}$ values. 
Fourth, for the manual THP cell growth/viability assays, GBM1 cells were dissociated with TrypLE, washed once with PBS and adjusted to 2000 cells in $100 \mu \mathrm{l}$ complete media per well and pipetted in technical triplicates of a 1:1000 drug dilutions on black 96-well plates (Nunc A/S, Roskilde, Denmark), resulting in concentrations of 10, 20, 30, 40 and $50 \mu \mathrm{M}$ of THP and a MeOH control. All assays were performed in biological triplicates.

Finally, apoptosis assays were performed with the Annexin V \& Dead Cell Kit (Merck, Darmstadt, Germany), proliferation assay with the Ki67 Proliferation Kit (Luminex), cell cycle assay with the Muse ${ }^{\circledR}$ Cell Cycle Kit (Luminex) and used with the Muse ${ }^{\circledR}$ Cell Analyzer flow cytometer, according to the protocol from the manufacturer. All assays were performed after $48 \mathrm{~h}$ incubation with the calculated half maximal inhibitory concentration $\left(\mathrm{IC}_{50}\right)$ drug concentration in biological triplicates.

Statistical analysis was performed with Prism Graphpad 8 software. The media control luminescence value average was rested from all the wells. The average luminescence value of the wild-type GBM1 containing wells was used as a control for normalization. The performed statistical tests depended on the number of variables; for two variables unpaired two-sided Student's $t$-test, and for more than two variables, two-sided one-way-ANOVA were used.

\section{Results}

We acquired data for all the library compounds (Supplementary Tables $1 \& 2$ ) and observed diverse responses and curve characteristics (Supplementary Figure 1A). Afterward, we made a logarithmic dose-response curve analysis and obtained $\mathrm{IC}_{50}$ values. With these variables, we then classified the drugs as compounds with intermediate potency - between 25 and $50 \%$ cell growth decrease and substances with high potency - $<75 \%$ cell growth decrease. Drugs with atypical dose-response curves and $\mathrm{IC}_{50}$ values not corresponding to the cell growth decrease were excluded for further consideration.

From repetitive drug-dose generated response profiles, 22 compounds exhibited a homogeneous decrease of cellular growth in the low micromolar concentration range compared with that of vehicle treatment control $(\mathrm{p} \leq 0.001)$ (Table 1; Figures 1; Supplementary $2 \& 3$ ). Out of which, 13 showed intermediate potency response and 9 exhibited high potency response (Figure 2). Out of these 22 drugs, nine were tested in preclinical studies related with glioblastoma, and ten drugs are investigated in clinical trials with glioblastoma patients. In addition, five of them have a confirmed mode of action related to neurotransmitter activity regulation including acetylcholine $(\mathrm{ACh})$, serotonin $(5-\mathrm{HT})$, dopamine and GABA signaling (Table 1).

From these compounds, we identified three novel repurposes for drugs without any previous reported annotation to neuro-oncology: THP, a ACh receptor antagonist used in symptomatic treatment of Parkinson's disease; homatropine, an ACh drug mainly used in ophthalmology for mydriasis induction, uveitis; as well as rizatriptan, a neurologic medication used primarily as an anti-migraine agent (Tables $1 \& 2$ ).

Furthermore, we classified the additional 19 drugs according to their clinical applications. Out of these, five were repurposed drugs that had main clinical application for neuropsychiatric conditions such as migraine, epilepsy, psychosis, schizophrenia and bipolar disorder among others (Supplementary Table 2). The rest of the drugs from this classification were mainly cytotoxic drugs used to treat a variety of cancers, including the DNA-alkylating agent temozolomide, the standard of care chemotherapeutic agent to treat glioblastoma patients.

With having the highest potency scoring in our screening list and given the novelty of this compound in the context of brain cancer, we chose THP for our validation experiments to manually confirm the effects found with the robot (Figure 1C). Sequential drug concentration to cell-growth assays reported logarithmic decrease of viability with increasing drug concentrations ( $\mathrm{p} \leq 0.001$; Figure $2 \mathrm{~A}$, calculated $\mathrm{IC}_{50}$ of $\sim 20 \mu \mathrm{M}$ ). We then went ahead and performed mode of action analysis. After $48 \mathrm{~h}$ of incubation of the cells with the $\mathrm{IC}_{50}$ dose of THP, there was a $19 \%$ increase in apoptosis compared with control $(\mathrm{p} \leq 0.001)$; supported by an increase of cells containing shredded DNA as revealed by higher $8 \%$ more subG1-fraction in our cell cycle analysis ( $\leq \leq 0.001)$. Moreover, THP causes $8 \%$ reduction of cell proliferation ( $\mathrm{p} \leq 0.05$ ), supported by an increase of $7 \%$ in G0/G1 of the treated cells in the cell cycle analysis ( $\mathrm{p} \leq 0.001)$ (Figure $2 \mathrm{~B}-\mathrm{D}$ ).

\section{Discussion \& conclusion}

Our data expand the recent accumulating evidence that brain tumors can be treated by neurotransmitter targeting compounds, in two main points. THP has not been reported to possess therapeutic potential against glioblastoma, thereby expanding the opportunities of pharmacological compounds in this context. We also show data characterizing the mode of action underlying this observation, thereby contributing to fundament the proposed 


\begin{tabular}{|c|c|c|c|c|c|}
\hline Group & Compound & Main indication & Mechanism & $\begin{array}{l}\text { Research phase in GBM } \\
\text { treatment }\end{array}$ & Table S2 correlation no. \\
\hline \multirow[t]{9}{*}{ High potency } & Palbociclib & Breast cancer & CDK inhibitor (CDK4/6) & Clinical trial & 1 \\
\hline & Trihexyphenidyl & Parkinson's disease & Anticholinergic & None & 2 \\
\hline & Clonidine & Arterial hypertension & $\begin{array}{l}\text { Central } \\
\text { alpha-adrenoceptor } \\
\text { agonist }\end{array}$ & Pre-clinical & 3 \\
\hline & Nilotinib & $\begin{array}{l}\text { Leukemia and } \\
\text { Philadelphia positive } \\
\text { chronic myeloid }\end{array}$ & $\begin{array}{l}\mathrm{BCR} / \mathrm{ABL} \text { tyrosine kinase } \\
\text { inhibitor }\end{array}$ & Clinical trial & 4 \\
\hline & Homatropine & Mydriasis induction & Anticholinergic & None & 5 \\
\hline & Doxorubicin & Multiple types of cancers & $\begin{array}{l}\text { Anthracycline, topo } \\
\text { isomerase } 2 \text { inhibitor }\end{array}$ & Clinical trial & 6 \\
\hline & Brexpiprazole & Psychosis & $\begin{array}{l}\text { Serotonin-dopamine } \\
\text { activity modulator }\end{array}$ & Pre-clinical & 7 \\
\hline & Dasatinib & $\begin{array}{l}\text { Leukemia, Philadelphia } \\
\text { positive accute and } \\
\text { chronic }\end{array}$ & $\begin{array}{l}\text { Tyrosine kinase inhibitor, } \\
\text { SRC-family }\end{array}$ & Clinical trial & 8 \\
\hline & Nintedanib & Lung cancer & $\begin{array}{l}\text { FGFR and VEGFR protein } \\
\text { inhibitor }\end{array}$ & Clinical trial & 9 \\
\hline \multirow[t]{13}{*}{ Intermediate Potency } & Vinblastine & Multiple types of cancers & Antimicrotubule & Clinical trial & 10 \\
\hline & Imiquimod & Skin cancer & $\begin{array}{l}\text { Immune response } \\
\text { modifier }\end{array}$ & Clinical trial (indirect*) & 11 \\
\hline & Phenoxybenzamine & Arterial hypertension & $\begin{array}{l}\text { Alpha-adrenoceptor } \\
\text { blocker }\end{array}$ & Pre-clinical & 12 \\
\hline & Rizatriptan & Migraine & Serotonin agonist & None & 13 \\
\hline & Letrozole & Breast cancer & Aromatase inhibitor & Pre-clinical & 14 \\
\hline & Divalproex & Psychosis/epilepsy & $\begin{array}{l}\text { GABA agonist/histone } \\
\text { deacetylase inhibitor }\end{array}$ & Pre-clinical & 15 \\
\hline & Regorafenib & Multiple types of cancers & VEGFR protein inhibitor & Pre-clinical & 16 \\
\hline & Everolimus & Multiple types of cancers & mTOR inhibitor & Clinical trial & 17 \\
\hline & Paclitaxel & Multiple types of cancers & Antimicrotubule & Pre-clinical & 18 \\
\hline & Romidepsin & Leukemia & $\begin{array}{l}\text { Histone deacetylase } \\
\text { inhibitor }\end{array}$ & Clinical trial & 19 \\
\hline & Topotecan & Multiple types of cancers & Topoisomerase 1 inhibitor & Pre-clinical & 20 \\
\hline & Gefitinib & Lung cancer & EGFR inhibitor & Pre-clinical & 21 \\
\hline & Temozolomide & Glioblastoma & Alkylate/methylate DNA & Clinical use & 22 \\
\hline
\end{tabular}

\section{Table 2. Repurpose suggestion of drug and basic substance characteristics.}

\begin{tabular}{|c|c|c|c|c|c|c|c|c|}
\hline & \multicolumn{3}{|c|}{ Molecular properties } & \multicolumn{4}{|c|}{ Clinical properties } & \multirow[t]{2}{*}{ Ref. } \\
\hline & $\begin{array}{l}\text { Molecular 3D } \\
\text { stucture }\end{array}$ & $\begin{array}{l}\text { Molecular } \\
\text { formula }\end{array}$ & $\begin{array}{l}\text { Molecular } \\
\text { weight }\end{array}$ & $\begin{array}{l}\text { Mechanism of } \\
\text { action }\end{array}$ & $\begin{array}{l}\text { Brands/other } \\
\text { names }\end{array}$ & Indications & Adult dosing & \\
\hline Trihexyphenidyl & & $\mathrm{C}_{20} \mathrm{H}_{31} \mathrm{NO}$ & $301.5 \mathrm{~g} / \mathrm{mol}$ & $\begin{array}{l}\text { Muscarinic } \\
\text { receptor-ACh } \\
\text { antagonist }\end{array}$ & Artane, Trihex & $\begin{array}{l}\text { Parkinsonism } \\
\text { and } \\
\text { extrapyramidal } \\
\text { symptoms }\end{array}$ & $\begin{array}{l}\text { Up to } \\
15 \mathrm{mg} / \text { day, oral } \\
\text { administration }\end{array}$ & [11] \\
\hline Homatropine & & $\mathrm{C}_{16} \mathrm{H}_{21} \mathrm{NO}_{3}$ & $275.34 \mathrm{~g} / \mathrm{mol}$ & Anticholinergic & $\begin{array}{l}\text { Isopto } \\
\text { Homatropine }\end{array}$ & $\begin{array}{l}\text { Mydriasis, } \\
\text { uveitis }\end{array}$ & $\begin{array}{l}\text { Up to } 5 \text { daily } \\
\text { drops from } 2 \% \\
\text { ocular solution }\end{array}$ & [11] \\
\hline Rizatriptan & & $\mathrm{C}_{15} \mathrm{H}_{19} \mathrm{~N}_{5}$ & $269.34 \mathrm{~g} / \mathrm{mol}$ & 5-HT agonist & Maxalt & $\begin{array}{l}\text { Migraine } \\
\text { headache }\end{array}$ & $\begin{array}{l}\text { Up to } \\
30 \mathrm{mg} / \text { day, oral } \\
\text { administration }\end{array}$ & [11] \\
\hline
\end{tabular}



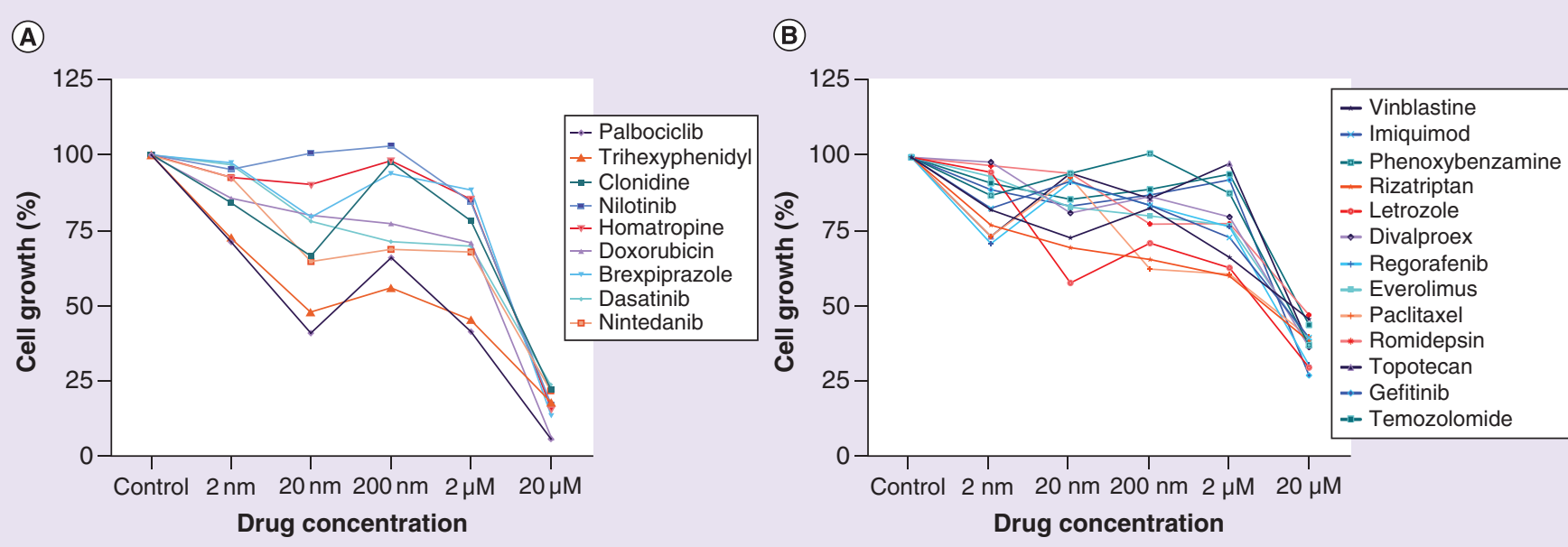

(C)
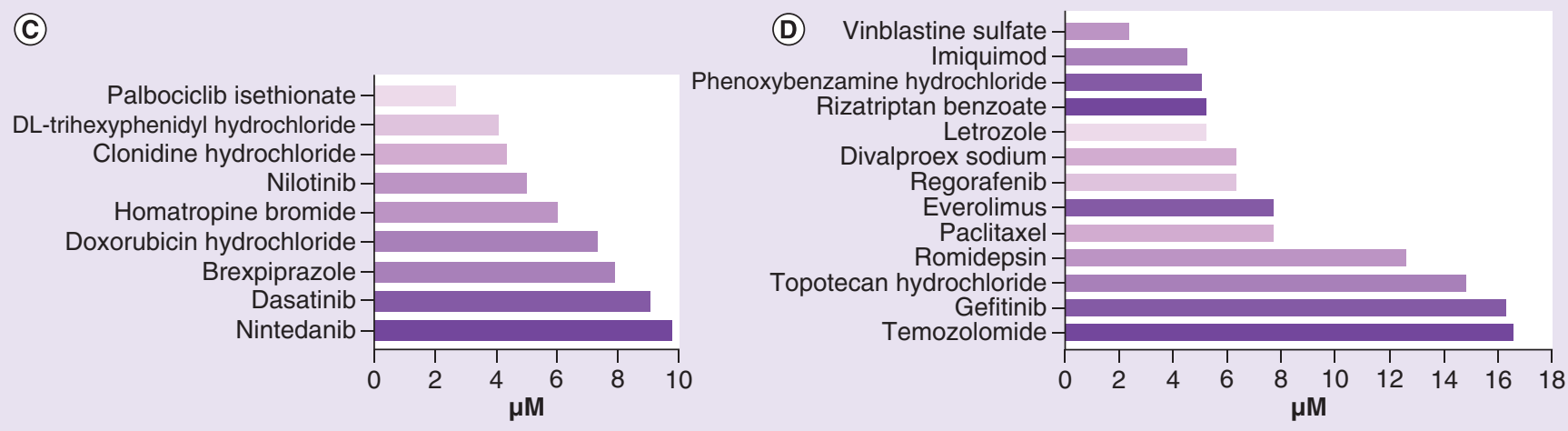

Figure 1. Compound response classification in robotic screening assay. (A) High potency drugs with $>75 \%$ cell growth decrease. (B) Intermediate potency drugs between 25 and $50 \%$ cell growth decrease. (C) IC 50 calculation for high potency drugs with the validated drug trihexyphenidyl highlighted. (D) $\mathrm{IC}_{50}$ calculation for intermediate potency drugs.

$\mathrm{IC}_{50}$ : Half maximal inhibitory concentration.

drug repurposing. Second, we extend the little existing data that the stem cell population in glioblastoma can be effectively treated with neurotransmitter pathway-targeting chemotherapy [5]. THP is a Parkinson's disease approved treatment with a mACh/ACh modulating mode of action. This mechanism has been described as a glioblastoma disease modulator in recent literature [4], as well as other similar mechanisms, such as monoamines which include 5-HT, dopamine and norepinephrine [6,12]. Our results are in line with recently accumulating evidence that neurotransmitter biology promotes glioblastoma development [13].

We are aware that cell models only simplify the complexity of the disease and lack pathophysiological recapitulation of the tumor microenvironment, therefore results must be considered as an abstract guidance. The authors note that a 3D model system, more commonly referred to as HSR-GBM1 and derived from a single tumor of a patient operated in Milan, Italy, was used in this study. Those spheroidic systems are suggested to most closely recapitulate tumor conditions in vitro [14]. We acknowledge that our data cannot exclude that THP toxicity is caused by off-target effects and does not affect neurotransmitter signaling or members of the neurotransmitter signaling pathways in glioblastoma. Further characterization of the response of glioblastoma cells to the drug, such as through pharmacometabolomics [15] shall be conducted to validate target specificity and is required before this novel approach would be applied in the management of this fatal disease. Even if target specificity cannot be confirmed, clinical testing could possibly be proceeded since many clinical cancer drugs act in an unknown off-target way [16].

From a clinical-translational prospective, we think that this technology would be useful to determine personal chemo-responsome of primary cells freshly derived from surgical resection specimens. Our robotics complete the 
(A)

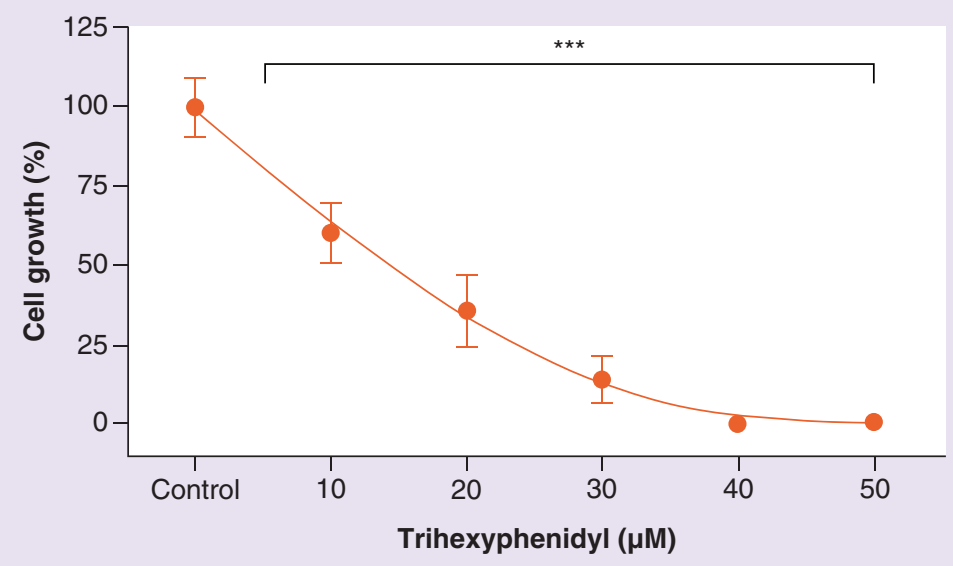

(C)

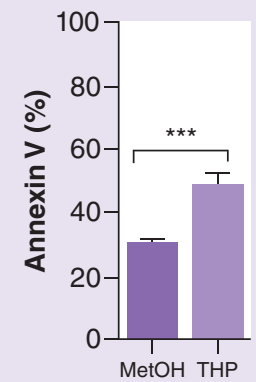

Control (MeOH): apoptosis profile

4 Dead Late apop./dead

$3-25.75 \% \quad \begin{aligned} & 12.20 \% \\ & \end{aligned}$

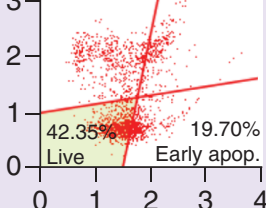

Live Annexin V Apoptotic

Trihexyphenidyl:

Apoptosis profile

4 Dead Late apop./dead

$3-24.20 \% \quad 23.95 \%$

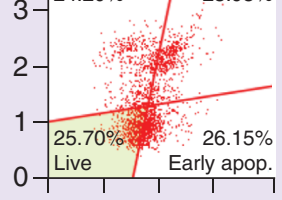

$\begin{array}{lllll}0 & 1 & 2 & 3 & 4\end{array}$

Live Annexin $\mathrm{V}$ Apoptotic
(B)
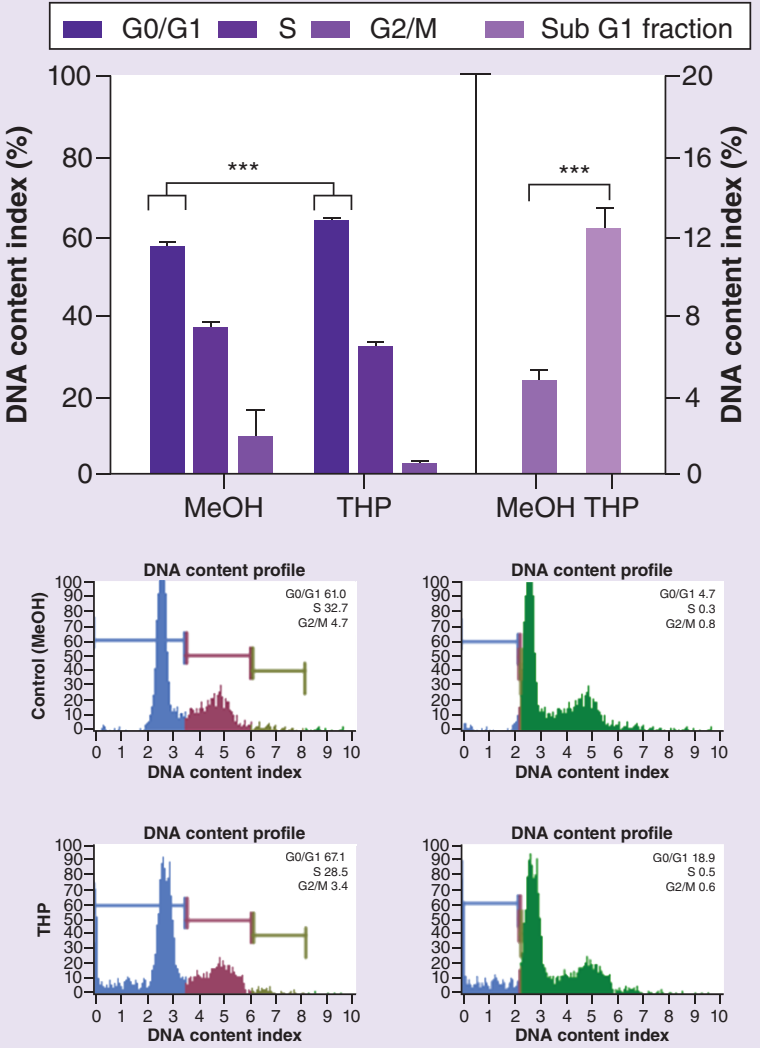

(D)
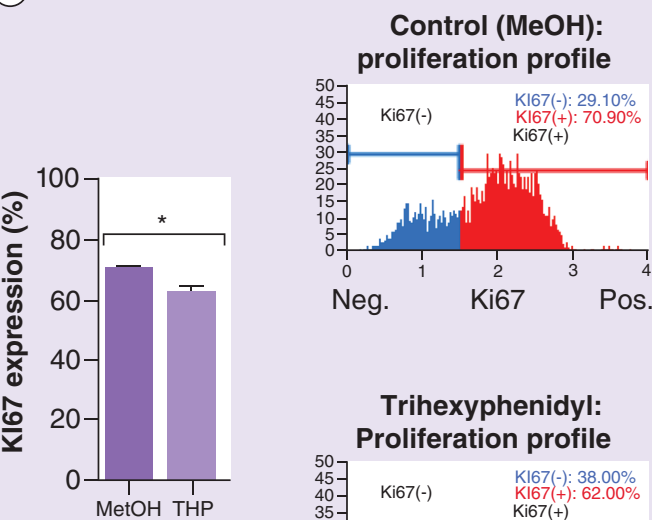

Trihexyphenidyl: Proliferation profile

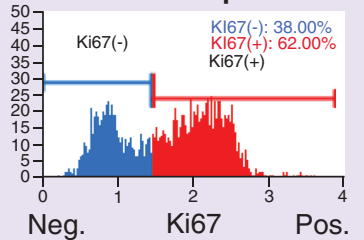

Figure 2. Targeted manual validation of robot screening results (trihexyphenidyl). (A) Cytotoxic effect of Trihexyphenidyl on GBM1 measured with normalized-to-control CellTiter-Glo ${ }^{\circledR}$ luminescence. (B) Increase of $8 \%$ of the apoptosis indicator subG1-fraction against $\mathrm{MeOH}$ control $(p \leq 0.001)$, significant increase of $7 \%$ in $\mathrm{G0} / \mathrm{G} 1$ of the treated cells in the cell cycle against MeOH control ( $p \leq 0.001)$ and flow cytometry gating. (C) Apoptosis increase and flow cytometry gating against $\mathrm{MeOH}$ control $(p \leq 0.001)$. (D) Proliferation decrease $(p \leq 0.05)$ supported by increase in G0/G1 in cell cycle results. All after $48 \mathrm{~h}$ drug exposure in GBM1 cell line. Unpaired two-sided student T test.

${ }^{*} \mathrm{p}<0.05 ;{ }^{* *} \mathrm{p}<0.01 ; * * * \mathrm{p}<0.001$.

$\mathrm{MeOH}$ : Methanol. 
list of liquid handling devices to do drug testing on tumors in vitro [2,17], thereby allowing this approach to be implementable in different lab settings and suitable for a variety of disease types and disease modeling strategies. We argue that our system will also be useful for testing drug resistance on more complex cell model culture systems that require pre-coating of culture plates - such as human induced pluripotent stem cells - mainly due to the detailed and programmable pipetting basis of liquid transfer in our device, which emulate manual pipetting on a high scale and cannot be facilitated by printing-based drug screening assays [18]. We considered the identification of known anti-glioblastoma drugs among the 22 identified effective treatments, as an additional validation indicator for our screening method.

Informing patients with advanced stages of the disease about individually tailored and clinical feasible treatment options, as an alternative or addition to standard of care treatment, represents an innovation mark for modern treatment centers. Given the overall challenges in glioblastoma therapy with standard of care, this tool at least opens the opportunity of discussion to improve treatment based on functional and technological fundaments. Furthermore, since the costs to execute such a screening are considerably low (approximately 350 EUR including all consumables, media and drugs; excluding personnel costs), we think that it could be ethical and economically feasible to include this in standard diagnostics for selected patients such as those with recurring glioblastoma and cerebral metastasis. We propose the utilization of this technology in drug discovery and personalized medicine.

Moreover, we note that our technology development project is well in line with recently stated consensus findings for research integrity [19]; and given the opportunity that we count with simple embedment of the robot-acquired electronic data in modern data -storage, -reporting and -archiving strategies, we hypothesize that the inclusion of lab-ware automation in academic laboratory routine is a useful strategy to improve reproducibility and transparency in preclinical research [20].

\section{Summary points}

- We extend the recent accumulating evidence that using a neurotransmitter targeting strategy is an innovative treatment route for glioblastoma and extend it with two principle novelties:

- We identified a previously unrecognized, clinical approved neurotransmitter-targeting drug to possess therapeutic effect on glioblastoma.

- We found that following the scope of using anti-neurotransmitter directed treatment kills stem cells in glioblastoma.

- We developed a robotic strategy to score therapy resistance in vitro in mid- to large-scale ranges.

- The pipetting fundaments of liquid aspiration and dispersion will allow the application in more complex culture systems that require coating of the cell culture plate.

- In this context, the technology is superior than printing-based liquid handling solutions.

- Our technology is well in line with recent stated guidelines on research integrity, addressing transparency and reporting of experimental studies.

- We propose the utilization of this technology in drug discovery and personalized medicine.

Supplementary data

To view the supplementary data that accompany this paper please visit the journal website at: www.futuremedicine.com/doi/suppl/10.2217/cns-2020-0004

\section{Author contributions}

Conceptualization: UD Kahlert, S Muhammad; MA Kamp, W Zhang; methodology: UD Kahlert, I Fischer, A Vargas-Toscano and M Hewera; software: UD Kahlert and A Vargas-Toscano; validation: A Vargas-Toscano and A-N Nickel; formal analysis: A VargasToscano, M Hewera, A-C Nickel; investigation: A Vargas-Toscano; resources, UD Kahlert, H-J Steiger, D Hänggi; data curation: A Vargas-Toscano; writing-original draft preparation: A Vargas-Toscano, UD Kahlert, W Zhang and D Khan; writing-review and editing: all authors; visualization: A Vargas-Toscano; supervision, UD Kahlert; project administration: UD Kahlert; funding acquisition: UD Kahlert, H-J Steiger, D Hänggi. All authors have read and agreed to the published version of the manuscript.

\section{Acknowledgments}

The authors acknowledge S Weggen, Institute for Neuropathology at Heinrich-Heine University, Düsseldorf for kindly providing the robotic related devices used for the experiments. 
Financial \& competing interests disclosure

A Vargas-Toscano is supported by the Catholic Academic Exchange Service of the German Catholic Church (KAAD). The work of UD Kahlert is supported by the Federal Ministry of Education and Research (BMBF KZ 03VP03791), the VolkswagenStiftung, the Hempel Family Foundation, the Brigitte-and Dr. Konstanze Wegener Foundation and the Sino-German Center for Science Promotion. The authors have no other relevant affiliations or financial involvement with any organization or entity with a financial interest in or financial conflict with the subject matter or materials discussed in the manuscript apart from those disclosed.

No writing assistance was utilized in the production of this manuscript.

Ethical conduct of research

The authors state that they have obtained appropriate institutional review board approval or have followed the principles outlined in the Declaration of Helsinki.

Open access

This work is licensed under the Attribution-NonCommercial-NoDerivatives 4.0 Unported License. To view a copy of this license, visit http://creativecommons.org/licenses/by-nc-nd/4.0/

\section{References}

Papers of special note have been highlighted as: $\bullet$ of interest; $\bullet \bullet$ of considerable interest

1. Gorshkov K, Chen CZ, Marshall RE et al. Advancing precision medicine with personalized drug screening. Drug Discov. Today 24(1), 272-278 (2019).

- Reports relevance of tailored chemotherapy.

2. Skaga E, Kulesskiy E, Fayzullin A et al. Intertumoral heterogeneity in patient-specific drug sensitivities in treatment-naïve glioblastoma. BMC Cancer 19, 628 (2019).

3. Stupp R, Mason WP, van den Bent MJ et al. Radiotherapy plus concomitant and adjuvant temozolomide for glioblastoma. $N$. Engl. J. Med. 352(10), 987-996 (2005).

4. Thompson EG, Sontheimer H. Acetylcholine receptor activation as a modulator of glioblastoma invasion. Cells 8(10), E1203 (2019).

-• Reports relation between glioblastoma and the brain neurotransmitter microenvironment.

5. Caragher SP, Shireman JM, Huang M et al. Activation of dopamine receptor 2 prompts transcriptomic and metabolic plasticity in glioblastoma. J. Neurosci. 39(11), 1982-1993 (2019).

6. Jiang SH, Hu LP, Wang X, Li J, Zhang ZG. Neurotransmitters: emerging targets in cancer. Oncogene 39(3), 503-515 (2020).

7. Bogue R. Robots in the laboratory: a review of applications. Ind. Robot 39(2), 113-119 (2012).

-. Emphasizes relevance of robotic technologies in laboratories and routine diagnostics.

8. Fan X, Khaki L, Zhu TS et al. NOTCH pathway blockade depletes CD133-positive glioblastoma cells and inhibits growth of tumor neurospheres and xenografts. Stem Cells 28(1), 5-16 (2010).

9. Kahlert UD, Suwala AK, Raabe EH et al. ZEB1 promotes invasion in human fetal neural stem cells and hypoxic glioma neurospheres. Brain Pathol. 25(6), 724-732 (2015).

10. Kahlert UD, Maciaczyk D, Dai F et al. Resistance to hypoxia-induced, BNIP3-mediated cell death contributes to an increase in a CD133-positive cell population in human glioblastomas in vitro. J. Neuropathol. Exp. Neurol. 71(12), 1086-1099 (2012).

11. National Center for Biotechnology Information. PubChem Database. https://pubchem.ncbi.nlm.nih.gov/

12. Beaulieu JM, Gainetdinov RR. The physiology, signaling, and pharmacology of dopamine receptors. Pharmacol. Rev. 63(1), 182-217 (2011).

13. Venkataramani V, Tanev DI, Strahle C et al. Glutamatergic synaptic input to glioma cells drives brain tumour progression. Nature 573(7775), 532-538 (2019).

-• Reports brain tumor progression under neurotransmitter microenvironment.

14. Brancato V, Oliveira JM, Correlo VM, Reis RL, Kundu SC. Could 3D models of cancer enhance drug screening? Biomaterials 232, 119744 (2020).

15. Koch K, Hartmann R, Tsiampali J et al. A comparative pharmaco-metabolomic study of glutaminase inhibitors in glioma stem-like cells confirms biological effectiveness but reveals differences in target-specificity. Cell Death Discov 6, 20 (2020).

16. Lin A, Giuliano CJ, Palladino A et al. Off-target toxicity is a common mechanism of action of cancer drugs undergoing clinical trials. Sci. Transl. Med. 11(509), eaaw8412 (2019).

17. Skaga E, Kulesskiy E, Brynjulvsen $\mathrm{M}$ et al. Feasibility study of using high-throughput drug sensitivity testing to target recurrent glioblastoma stem cells for individualized treatment. Clin. Transl. Med. 8(1), 33 (2019). 
18. Tseng H, Gage JA, Shen T et al. A spheroid toxicity assay using magnetic 3D bioprinting and real-time mobile device-based imaging. Sci. Rep. 5, 13987 (2015).

19. Lancet T. Assessing researchers with a focus on research integrity. Lancet 393(10181), P1570 (2019).

20. Yeow J, Ng PK, Tan KS, Chin TS, Lim WY. Effects of stress, repetition, fatigue and work environment on human error in manufacturing industries. J. Appl. Sci. 14(24), 3464-3471 (2014). 
